\title{
Beginning teacher experiences in Lao PDR: From research to the development of a professional development program
}

\author{
Sivilay Phommachanh \\ Pakse Teacher Training College, Laos \\ sivilay30@yahoo.co
}

\section{Michele Willsher}

Batchelor Institute of Indigenous Tertiary

Education

michele.willsher@batchelor.edu.au

\begin{abstract}
This article describes how an ethnographic research study paved the way for the design of a Beginning Teacher Support (BTS) program. The aim of the research was to understand the world of beginning teachers in Lao PDR (Laos). Drawing on the work by Lave and Wenger (1991) of situated learning, the research documented the affordances and constraints of beginning teachers as well their social, political and cultural work contexts. As understanding developed, the Australian researcher and Lao educators agreed that the findings should be used to "identify strategic points of intervention" (Denzin, 2001, p. 2) and inform the design of a professional development program that could support beginning teachers. This collaborative work resulted in the design of a multi-dimensional support program, which aims to support teachers as they embark upon their careers.
\end{abstract}

\section{Introduction}

Learning to teach is regarded as a continuous process that extends across a teacher's entire professional career (Bransford, Darling-Hammond \& LePage, 2005; Villegas-Reimers, 2003). More recently, providing specific support for beginning teachers is acknowledged as particularly critical, especially in those countries where pre-service programs are poorly resourced (UNESCO, 2010). This support is also deemed crucial as research has highlighted how political, social and cultural factors in the workplace affect the ways beginning teachers teach (Calderhead \& Shorrock, 1997; Day, 1999; Flores, 2001).

The ethnographic research which investigated the worlds of beginning teachers in Laos was initially planned as a study situated in the interpretive paradigm aimed to understand rather than change the situation. However as the research progressed, collaboration with the local Lao educators who had given the research informal support, became more formal. The subsequent discussion of the findings with local educators generated a desire for change, and as a consequence of much deliberation and planning, a Beginning Teacher Support (BTS) program developed.

Both the research and the BTS program were undertaken in Laos. At 6.2 million people, Laos has the smallest population of any country in South-East Asia, however it remains one of the poorest countries in the world. In 2011, Laos was ranked $138^{\text {th }}$ out of 187 countries on the Human Development Index (UNDP, 2011). In the last ten years, the country has made significant reforms to its education system. These reforms have focused on both school and teacher education, and have received significant support from the Australian government. 


\section{The research study}

The research study was undertaken to find out what beginning teachers in Laos do and think about their work. Four research questions were framed, which encapsulate the study:

1. What expectations do trainee-teachers have about the roles they will perform and the responsibilities they will have as beginning teachers?

2. What is the nature of the professional experiences beginning teachers have during their first year of teaching?

3. In what ways and to what extent do beginning teachers develop their teaching practices during their first year of teaching?

4. What are the professional development needs of beginning teachers?

While there is a wealth of studies in developed countries on teacher practices, there have been no ethnographic case studies looking into the worlds of rural teachers in Laos. It was decided that an understanding of the lives of beginning teachers in Laos could best be obtained through an eclectic approach adopting methods central to ethnography as proposed by Spindler (1982), Emerson, Fretz, \& Shaw (1995), and Wolcott (2008), and to educational case study methodology developed by Stake (1995), Bassey (1999) and Yin (2009).

While an ethnographic case study does not aim for generalisation across wider populations, the value of the case and its presentations allow readers to compare their situation with what has been found. As Stake (2005, p. 460) argues, the value of providing case records is "... not to represent the world, but to represent the case". It is anticipated the observed practices, the reported challenges and aspirations of the beginning teachers provided in the case study, allows Lao educators to compare and contrast their own extensive experiences in schools.

Over an 18-month period of fieldwork, observations were undertaken and interviews conducted to construct the case studies. An initial period of six months was spent at the Pakse Teachers' Training College (TTC) in Champasak Province, following a cohort of trainee-teachers over the concluding half of their one-year teacher training diploma course. Four of these trainees, now beginning teachers, participated for a further twelve months in the study. During this time, the researcher made a series of week-long visits to the four different villages where the teachers had been posted. In total, 155 lessons were formally observed during the visits, 121 semistructured interviews conducted and extensive journal notes kept of informal observations and conversations.

Detailed case record descriptions were written for each of the four beginning teachers which helped to develop an intimate knowledge of each setting. Interview and observational data was analysed from both within as well as across cases. Within each case, comparisons were made about the teachers' attitudes, experiences and teaching practices as the year progressed. Across the cases, data was compared to find any similarities or differences between the four teachers' attitudes and experiences.

The ethnographic case study research was intent on understanding the situation, during the 18 months of field work, but as the data was being collected, an ethical dilemma emerged How to respond to the beginning teachers' questions about their teaching? From discussions with the participants it was agreed that instead of providing direct feedback during the field visits, a professional activity would be planned to provide feedback about their work and to thank them for their involvement in the study.

Towards the end of the field-work stage, the researcher engaged in regular discussions with staff from the Pakse Teacher Training College about the research findings, and a formalised 
support program was designed. This program commenced with an opportunity for immediate feedback and resulted in a week-long workshop, not just for the four participants of the study but for another 26 beginning teachers who were also at the end of their first year of teaching. Funding to deliver this workshop was sought from Australian People for Health Education and Development Abroad (APHEDA), an Australian Non-Government Organisation (NGO). The successful delivery of this initial workshop confirmed the commencement of a BTS.

The following section of this paper discusses the research findings and explains the dimensions of the professional development program.

\section{The research findings}

The study mapped how four teachers adapted their teaching practices to accommodate the realities they encountered in their classrooms, schools and villages. Like many others starting out in professional life, the four young people at the centre of this study held high ideals and aspirations for themselves and their careers. While they each worked to complete the tasks of teaching they were guided primarily by the example of their senior colleagues and the principal to reproduce existing practices.

Interviews held prior to graduation with pre-service teachers revealed an optimism to try new ways of teaching which were different to how they had been taught at school. Once in their schools, however, all four teachers reported they saw their colleagues only using traditional teaching methods. When questioned about their interactions with other staff, they also commented how they were reluctant to ask too many questions of their colleagues about teaching. As one teacher explained, "they might think that I didn't learn anything in College". Another of the four teachers in the study spoke about her attempts to ask other staff for help to incorporate more modern methods of teaching. While she acknowledged they supported her emotionally, the comment below suggests a reason for the limited pedagogical support.

At first I asked questions from the other staff, but they didn't seem to be interested in my questions and so I stopped. It took me a while to realise, but after a few months I got the feeling that they didn't have any suggestions.

An analysis of the 155 lesson observation records conducted across the teachers' first year of teaching, revealed traditional teaching practices dominated their classrooms. On average, only $15 \%$ of their lessons included some type of learning activity, only $20 \%$ of lessons involved using a teaching aid other than the blackboard or textbook, and only $7 \%$ of lessons involved the students working in small groups. Talk was mostly comprised of teachers asking questions which required their students to recall information from the textbook. In the majority of lessons, students were observed spending large amounts of time copying or reciting work from the blackboard.

All lessons were focused on completing the textbook lesson and so any activity which might possibly lengthen the lesson time was avoided. Similarly, talk by the students which might lengthen the lesson time would be often cut short. Teachers were reluctant to deviate from the questions set out in the textbook. Even in the lessons when teaching aids were used, they were predominantly handled by the teacher not the students. Group work often meant students simply sat in group formations rather than being given an authentic task to complete collaboratively. 
While the beginning teachers reported they had been told about modern teaching practices by both lecturers and their principals, one teacher explained:

I now realize that one of the main problems is that I never actually saw the methods they talked about in the College being put into practice, neither during the course or after I started work.

She then elaborated on her emotional state:

I feel sad that I haven't taught more children to read - and feel disappointed that it's just so hard to teach my class. There's no one who is really interested in talking about teaching with me and how I can help my students learn.

It is understandable that being unconfident and without support, the beginning teachers' initial enthusiasm for at least trying out teaching strategies to encourage active learning soon stopped. The study revealed if the beginning teachers were to avoid social isolation they had to fit in. The appropriation of surrounding practices was gradual as different teachers adopted different practices at different times. By the end of the year though, three of the four beginning teachers were generally teaching like the rest of the staff in their school.

Lave and Wenger (1991) contend it is through situated learning that individuals acquire knowledge and skills as they participate alongside others in carrying out authentic tasks embedded in the workplace. The process, which they call legitimate peripheral participation, gives rise to learning which is acquired gradually and cumulatively. From this perspective the new teachers were supported by more experienced teachers to learn the expected practices of the workplace and become part of the community of practice.

The professional struggles each of the beginning teachers encountered over their first year are encapsulated in the study as five dilemmas:

1. whether or not to respond to requests from colleagues for help

2. whether to report student progress accurately or not

3. whether to seek professional help from colleagues or whether to remain silent

4. whether to employ learner-centred methods or whether to keep to traditional methods

5. whether to respond to student learning needs or just simply teach to the textbook like everyone else.

The four beginning teachers, unpaid 'volunteers' with no job security, had little resilience when faced with such choices.

Amidst these dilemmas, each of the beginning teachers did attempt to help students learn. While their strategies were lodged within their youthful enthusiasm they were constrained by the obstacles of heavy workloads, large class sizes, limited resources, and a wide range of learning abilities in each class. The eight most common strategies adopted by the new teachers and identified in the study were:

1. setting and marking homework

2. using break times to allow students to catch up

3. using non-core subject time to teach literacy and numeracy

4. setting tasks according to the abilities of the students 
5. organising students to check each other's work

6. talking to students about the reasons for learning

7. talking to parents about their children and enlisting their support

8. staying in the classroom throughout the whole lesson.

Analysis of the data found the four beginning teachers experienced similar pressures from their colleagues to conform to the established patterns and behaviours in their respective schools. In effect, the school as a community of practice, with all its potential for nurture and guidance, operated as a community of compliance.

Lave and Wenger's (1991) theory of legitimate peripheral participation, explains in the process of learning it is not only individuals who are transformed, but individuals can work to influence the established practices of the community of practice. In their words, "participation does not take place in a static context" (p. 116). A similar perspective is found in the work of Rogoff (2003) who argues that through the participation of individuals in socio-cultural activities, communities can also change. Examples of the transformative potential of a 'community of practice' are provided by Lee and Roth (2003), and by Cummings (2008) who describes how both the 'newcomers' as well as those with whom they interact "... undergo degrees of change and/or transformation that impact on their communities as well as themselves" (p. 9).

A study conducted in the USA by Borko (2004) has shown that in some cultures when new entrants to the workplace are considered to be of equal status with other members and when their viewpoints are welcomed and considered, the transformative power of the community of practice is realised. In contrast to the works cited above, this study found the beginning teachers had little choice to do anything other than contribute to the reproduction of the dominant practices if they were going to maintain social harmony and achieve their goal of permanency. The study provides a clear picture of how cultural norms and embedded power relationships within schools can conspire to limit the transformative potential of the community of practice. By the end of the year, the four young teachers in this study, had mostly adapted to the expectations of their local situations. One teacher who had stopped trying to implement the practices learnt at College explained her reasons:

There's not much incentive to work hard - just to work like the others and to fit in. If I did what I think I should be doing they would think I was strange.

In the Lao villages where the four teachers lived, Theravada Buddhism was at the centre. In such communities, Buddhist values and Buddhist beliefs play a dominant role in the way people lead their lives. Society is hierarchical with social status playing an important organising role. Primary values of interest to this study are respect for elders such as parents and older relatives, and deference to authority figures such as Village Committee members, teachers and government officials. These values also extend to include the veneration of monks. Vistarini (1994) characterises Lao culture as one which "stresses harmonious relationships, respect for age and wisdom and tolerance for other people" (p. 294), a depiction which is supported in Kittiphanh's (2011) work, while Stuart-Fox and Mixay (2010, p.12) comment "Buddhism permeates Lao culture through and through. It accounts not just for the rituals that Lao perform throughout the year, but also for their acceptance of life and tolerance of others". In general terms, people are non-confrontational and deference is expected and paid to those in authority. In the context of the school, students are respectful of the authority of their teachers, and the teachers observe and maintain the social distinctions that uphold the school principal in a position of respect. In the classrooms, the message of the textbooks is one of "obedience to superiors, patriotism, cleanliness" (Evans, 1998, p. 166), and in this the 
school serves to reproduce an idealised vision of the society and its people. The beginning teachers, having grown up under this conservative ideology, now became the purveyors and transmitters of its 'truths'.

Upon arrival in their schools, each of the beginning teachers was located at the bottom of the hierarchical ladder of the education system, in the position of volunteer teacher. Like the older teachers before them, several of whom spoke of their own struggles to become a teacher, the four beginning teachers would also have to 'wait their time' until they became permanent. The reward to both them and their families for this waiting would be a regular, albeit small, monthly salary, some state-assisted medical care, and an official teaching position. However, until the beginning teachers had their applications processed and approved, they engaged with senior staff, particularly the principals, knowing they were reliant on them for providing favourable reports to the District Education Bureau officials as well as mustering support from the Village Committee in order to meet their daily needs.

The social strategy adopted by the beginning teachers of absorbing the surrounding practices and following the advice of their colleagues has been defined here as compliance and in the deferential and hierarchical society in which they lived this was the natural path to take. The dilemmas and the tensions they at first experienced were real enough, but their resolution was achieved simply by putting aside one half of the equation, and accepting and adopting the encompassing practices.

Listening to the beginning teachers talk and seeing what enthused them about their work as well as what made them despondent, provided a good point from which to start on the design of a program for teacher support. Outcomes of the study were two fold. The first was a set of recommendations for improving the quality of pre-service teacher education in Laos and the second was a set of recommendations aimed at developing a professional development support program. Both sets of recommendations were grounded in the social and cultural contexts of the schools where the beginning teachers studied and worked. It is the second set of recommendations, aimed at developing professional development program, which have been used as a foundation for local Lao educators to develop a BTS program.

\section{Discussion: The Beginning Teacher Support Program}

Sustained, ongoing collaboration between the researcher and TTC staff, resulted in the development of a support program set in the context of local need and resources. Through recognising the teaching skills these beginning teachers lacked, the 'culture of compliance' in which they worked and the hierarchical nature of the social, cultural and political system, a multi-dimensional support program was established. Therefore, as well as designing workshops specifically for addressing the pedagogical questions which beginning teachers asked, time was also assigned to involve those in positions of power - the principals and senior staff.

Even though the trainees had been told about a variety of new skills and modern teaching techniques in their teacher training program, once they had graduated and were in their own classrooms it became difficult to maintain the effort to implement practices that were different from their local school colleagues. Any program of support would therefore have to recognise the social and cultural contexts within which these teachers would go to work.

The teacher training college staff acknowledged the need to allocate appropriate time for principals and other senior teachers to understand the support program and to be involved. A key aspect of the successful introduction of the program revolved around developing the capacity of the senior school staff to understand the changes. As Hartwell (2008) clearly explains, the successful implementation of new programs requires leaders: 
... who are well grounded in the practice ... well placed to organise political support and resources; who have the power of persuasion; who have the respect of community members and local authorities; and who have a commitment to assure children's learning (p. 158).

Linked to the critical role the principal can play was the importance of building the internal capacity of all school staff (Stoll, 1999). The staff at the Pakse TTC believed the program should help develop positive relationships between teachers, and it should help support teacher morale. A similar position is advocated by Joyce and Showers (1995) who conclude:

Perhaps no change is more needed than the development of social arrangements that enable educators to work supportively together to help one another reflect on teaching, and help one another make sensible changes (p. 164).

With these considerations in mind, the BTS program has been designed around the idea that programs for beginning teachers need to consider the culture of the whole school. It is thus comprised of five features as described below.

\section{Intensive workshops for beginning teachers}

The TTC staff agreed intensive workshops needed to be organised for all beginning teachers at the end of their first six months of teaching. These workshops needed to focus on those specific pedagogical topics identified in the research.

Staff at the College facilitated the workshops and adopted a participatory approach where a range of topics were discussed and specialist advice provided. Initially, these topics were those identified in the research and included: the use of learner-centred approaches in the classroom; how to adapt the textbook for student learning; how to teach mathematics and Lao language in the early grades; how to manage group work for student learning; how to use authentic assessment practices; and how to effectively communicate with parents.

Beginning teachers were also encouraged to discuss case studies and to share their first year teaching experiences with TTC lecturers. The workshop timetable was flexible enough to take into account individual needs and interests of the group and to allow for other topics to be addressed.

These five-day workshops, held six months after starting work, have created opportunities for beginning teachers to learn from their peers and to develop peer-support networks. They are considered a key strategy for helping beginning teachers to build resilience and to sustain their enthusiasm and commitment to teaching.

\section{Workshops for principals and senior teachers in schools}

Professional Development workshops for Principals and Senior Teachers ${ }^{1}$ became a feature of the program after delivering the first intensive workshops for beginning teachers. The workshops are designed to help senior staff members understand and discuss the dilemmas encountered by beginning teachers and to consider strategies to support them. They are held separately from the workshops for beginning teachers in order to maintain confidentiality for beginning teachers.

1. At each primary school, one teacher, usually the most experienced, is designated the role of the academic teacher. This person is responsible for managing the teaching and learning, and supporting new staff to understand teaching responsibilities. 
The development of an induction handbook for all school staff

The initial workshop for beginning teachers was followed by the development of an induction handbook, which documented ideas for addressing common problems. In the second year of the program, this booklet was disseminated to all new teachers and was then discussed during the recall workshops held six months after starting work. This handbook is annually reviewed and modified in order to respond to changing curriculum and needs.

\section{Follow-up visits by staff from the Teacher Training College}

Visits are conducted by staff from the $\Pi \mathrm{TC}$ to schools where beginning teachers are employed. They encourage the building of stronger links between the pre-service program and ongoing professional development. They allow TTC staff to visit teachers in their local schools and to see for themselves problems and challenges. During these visits, staff learn about the current issues schools are encountering and consequently these experiences help to inform their teaching of pre-service teachers. More importantly, these site visits help to build trust and develop professional relationships with those teachers who are the most vulnerable.

\section{Continuous review and ongoing development of the program}

At the onset, the TTC staff members involved in the design of the program, agreed the program should be small scale and that lessons should be gathered during each new stage to inform the next.

The BTS program has continued since its inception in 2010. Initially involving just beginning teachers, it then moved to addressing their needs through involving principals and senior teachers. It has since expanded to a second TTC located in the southern province, Salavanh. A further initiative of the program involves the commencement of a telephone support-service which was planned for 2016.

While no formal evaluation has been carried out as to the program's effectiveness, anecdotal reports are positive, with teachers self-reporting on the ways the program has supported them to develop knowledge, skills and confidence. Beginning teachers have reported on the benefits of being able to meet with others who are facing similar challenges of settling into new schools. In the face of extraordinary circumstances, which include large class sizes, heavy workloads, limited resources and didactic teaching models, it is yet to be seen whether this support is having an effect on the quality of learning in the classroom. It is therefore now timely for a more formal review to take place.

\section{Conclusion}

The research and BTS support program have been forged through the collaborative efforts of an Australian researcher and Lao teacher educators working at the Pakse Teacher Training College in southern Laos. This collaboration has ensured the BTS program has developed to suit the cultural, social and political context of beginning teachers in Laos. In essence, it has helped beginning teachers develop a voice in a space where previously they were made to comply.

The BTS program initially delivered by the Pakse TTC and subsequently by the Salavanh TTC is now being discussed by other TTCs in Laos. The implication for policy and national practice in relation to professional support for the beginning teachers is continuing to evolve. With experiences in this new professional learning area now being gathered across Laos, it is hoped the program may soon become embedded in the government system and developed into a sustainable model for improving the quality of teaching in schools. 


\section{References}

Bassey, M. (1999). Case study research in educational settings. Berkshire: Open University Press.

Borko, H. (2004). Professional Development and Teacher Learning: Mapping the Terrain Educational Researcher, 33(8), 3-15.

Bransford, J., Darling-Hammond, L., \& LePage, P. (2005). Introduction. In J. Bransford \& L. DarlingHammond (Eds.), Preparing teachers for a changing world: What teachers should learn and be able to do (pp. 1-40). Jossey-Bass.

Calderhead, J., \& Shorrock, S. (1997). Understanding teacher education: Case studies in the professional development of beginning teachers. London: Falmer Press.

Cummings, W.K. (2008). Options to improve learning acquisition. In W. K. Cummings \& J. Williams (Eds.), Policy-making for education reform in developing countries: Policy, options and strategies (pp. 183-215). New York: Rowman and Littlefield Education.

Day, C. (1999). Developing teachers: The challenges of lifelong learning. London: Falmer Press.

Denzin, N.K. (2001). Interpretive interactionism (2nd edition). Thousand Oaks, CA: Sage.

Emerson, R.M., Fretz, R.I., \& Shaw, L.L. (1995). Writing ethnographic field notes. Chicago: University of Chicago Press.

Evans, G. (1998). The politics of ritual and remembrance: Laos since 1975. Chiang Mai: Silkworm Books.

Flores, M. (2001). Person and context in becoming a new teacher. Journal of Education for Teaching, 27(2), 135-148.

Hartwell, A. (2008). Learning for all: Alternative models and policy options. In W. K. Cummings \& J. Williams (Eds.), Policy-making for education reform in developing countries: Policy, options and strategy (pp. 141-183). New York: Rowman \& Littlefield Education.

Joyce, B., \& Showers, B. (1995). Student achievement through staff development (2nd edition). New York: Longman.

Kittiphanh, D. (2009). Teaching competency standards in the Lao PDR. Paper presented at the SEAMEO INNOTECH Conference: Teaching Competency Standards in Southeast Asian Countries, Manila.

Lave, J., \& Wenger, E. (1991). Situated learning: Legitimate peripheral participation. Cambridge: Cambridge University Press.

Lee, S., \& Roth, W. (2003). Becoming and Belonging: Learning qualitative research through legitimate peripheral participation. Forum: Qualitative Social Research, 4(2), 1-23.

Rogoff, B. (2003). The cultural nature of human development. Oxford: Oxford University Press.

Spindler, G. (1982). Doing the ethnography of schooling: Educational anthropology in action. New York: Holt, Rhinehart and Winston.

Stake, R.E. (1995). The art of case study research. Thousand Oaks, CA: Sage.

Stake, R.E. (2005). Qualitative case studies. In N. K. Denzin \& Y. S. Lincoln (Eds.), The Sage handbook of qualitative research (3rd edition, pp. 443-467). London: Sage.

Stoll, L. (1999). Realising our potential: Understanding and developing capacity for lasting improvement. School Effectiveness and School Improvement, 10(4), 503-532.

Stuart-Fox, M., \& Mixay, S. (2010). Festivals of Laos. Chiang Mai, Thailand: Silkworm Books. 
UNDP. (2011). The human development report. New York: United Nations Development Program.

UNESCO. (2010). Reaching the marginalised. EFA global monitoring report 2010. Paris, France \& Oxford, United Kingdom: United Nations Educational, Scientific and Cultural Organization \& Oxford University Press.

Villegas-Reimers, E. (2003). Teacher professional development: An international review of the literature. Paris, France: UNESCO, International Institute for Educational Planning.

Vistarini, W. (1994). Representations of Laos: Late nineteenth century French and Lao constructs. Unpublished PhD thesis. La Trobe University.

Wolcott, H. (2008). Ethnography: A Way of Seeing (2nd ed.). New York: Alta Mira Press.

Yin, R. (2009). Case study research (4th edition). Thousand Oaks, CA: Sage. 